\title{
Aggressive mucosa associated lymphoid tissue lymphomas are associated with mutations in $\mathrm{Bcl10}$
}

Willis TG, Jadayel DM, Du M-Q, et al. Bcl10 is involved in $t(1 ; 14)(\mathrm{p} 22 ; \mathrm{q} 32)$ of MALT $\mathrm{B}$ cell lymphoma and mutated in multiple tumor types. Cell 1999;96:35-45.

\begin{abstract}
MALT B cell lymphomas with $t(1 ; 14)(p 22 ; q 32)$ showed a recurrent breakpoint upstream of the promoter of a novel gene, $\mathrm{Bcl10} . \mathrm{Bcl10}$ is a cellular homolog of the equine herpesvirus-2 E10 gene: both contain an amino-terminal caspase recruitment domain (CARD) homologous to that found in several apoptotic molecules. Bcl10 and $\mathrm{E} 10$ activated $\mathrm{NF}-\kappa \mathrm{B}$ but caused apoptosis of 293 cells. Bcl10 expressed in a MALT lymphoma exhibited a frameshift mutation resulting in truncation distal to the CARD. Truncated $\mathrm{Bcl10}$ activated NF-кB but did not induce apoptosis. Wild-type $\mathrm{Bcl10}$ suppressed transformation, whereas mutant forms had lost this activity and displayed gain-of-function transforming activity. Similar mutations were detected in other tumor types, indicating that Bcl10 may be commonly involved in the pathogenesis of human malignancy.
\end{abstract}

\section{Comment}

Low grade B cell lymphomas of mucosa associated lymphoid tissue (MALT) are tumours with characteristically indolent behaviour. They have relatively low proliferation index, benign cellular morphology and histology, and the tumour cells are often interspersed among chronic inflammatory cells. ${ }^{1}$ Some cases of low grade gastric MALT lymphoma are dependent on local infection with Helicobacter pylori, compounding their image as very low grade malignancies. ${ }^{2}$ The advent of sensitive polymerase chain reaction methods however showed that these are indeed tumours which can advance, both in stage, and from low to high grade. ${ }^{3}$ Within this group of relatively non-threatening tumours, there are some clinically aggressive ones. Cells from some of these tumours proliferate spontaneously in tissue culture and have a chromosomal translocation between chromosome 1 and the immunoglobulin heavy chain locus on chromosome $14(\mathrm{t}(1 ; 14)(\mathrm{p} 22 ; \mathrm{q} 32)) .^{4-6}$ Tumours without the translocation die in culture. Willis et al have identified and described the properties of a novel gene, Bcl10, which is located at the chromosomal breakpoint. They characterised both wild type $B c l 10$ which maps to chromosome $1 \mathrm{p} 22$, and the mutated $B c l 10$ which was used by an aggressive MALT lymphoma variant. Mutation resulted in the production of a truncated protein with different functional properties.
Structurally, wild type Bcl10 protein consists of a caspase recruitment domain (CARD), which has significant homology with other known CARDs, ${ }^{7}$ and a novel distal amino acid sequence. Caspases are involved in the apoptotic pathway ${ }^{8}$ and it was hypothesised that Bcl10 could be functionally associated with this process, though CARD proteins can be either pro- or anti-apoptotic. In functional assays, wild type Bcl10 was shown to be weakly pro-apoptotic and it could also activate nuclear factor $(\mathrm{NF})$ $\kappa \mathrm{B}$. Activation of $\mathrm{NF}-\kappa \mathrm{B}$, a DNA binding factor, is the ultimate goal of many intracellular signalling pathways, and the consequence is considered to be pro-inflammatory. ${ }^{9}$ It was shown that, like p53, which is probably the most widely investigated tumour suppressor gene implicated in many malignant processes, wild type Bcl10 had tumour suppressor activity as it could inhibit cellular transformation by oncogenes in vitro. In contrast, the truncated Bcl10 mutants used by the aggressive MALT lymphoma variant had notably different properties in some of these assays, though they retained the capability to activate NF- $\mathrm{NB}$. Truncated Bcl10 was no longer pro-apoptotic, and not only did it fail to have tumour suppressor activity, evidence was presented that it has tumorigenic properties.

The precise role of truncated Bcl10 in the aggressive behaviour of this subset of MALT lymphomas is unclear. The characteristic behaviour may be due to the dissociation of activation of $\mathrm{NF}-\kappa \mathrm{B}$ and the pro-apoptotic activity as the truncated protein has lost the latter function only. Phorbol esters, chemicals which stimulate many cells in vitro, are known to activate NF- $\kappa \mathrm{B} .{ }^{9}$ Earlier studies have shown that aggressive variants of MALT lymphomas are refractory to the effects of phorbol esters ${ }^{6}$ and it is clear that the disruption of $\mathrm{Bcl} 10$ affects the intracellular signalling pathways in these tumours. In addition, the oncogenic activity of Bcl10 is likely to enhance tumour progression.

Mutations in Bcl10 were not restricted to aggressive variant MALT lymphomas; examples of $\mathrm{B}$ cell and $\mathrm{T}$ cell lymphomas of various histogenetic types with no $\mathrm{t}(1 ; 14)$ translocation, but with mutated $B c l 10$ were observed. In some cases, the mutations would be expected to result in the production of truncated protein. Remarkably, mutations in Bcl10 were also observed in cell lines derived from other groups of tumours with known association with abnormalities in chromosome $1 \mathrm{p} 22^{10}{ }^{11}$; three of three mesothelioma cell lines and three of three male germ cell tumours had significant mutations in Bcl10. By contrast, Bcl10 mutations were not observed in 15 breast, 11 pancreatic or 15 lung carcinoma cell lines. Although Willis et al's study was restricted to cell lines, there is a good chance that mutation of $\mathrm{Bcl} 10$ is a significant event in the evolution of at least some cases of mesothelioma and male germ cell tumours.

In conclusion, we can expect to see a frenzy of activity in $B c l 10$ research in the future. Aggressive MALT lymphoma, by its behaviour as a "wolf in sheep's clothing", has brought to the forefront a gene of great importance in oncology and tumour cell biology. 
J SPENCER Department of Histopathology, Guy's, King's and St Thomas'Medical School, St Thomas' Campus, Lambeth palace Road, London SE1 7EH, UK email:j.spencer@umds.ac.uk

1 Isaacson PG, Spencer J. The biology of low grade MALT lymphomas. $\mathcal{F}$ Clin Pathol 1995;48:395-7.

2 Wotherspoon AC, Doglioni C, Diss TC, et al. Regression of primary low-grade B cell gastric lymphoma of mucosa-associated lymphoid tissue type after eradication of Helicobacter pylori. Lancet 1993;342:575-7.

3 Peng H, Du M, Diss TC, et al. Genetic evidence for a clonal link between low and high grade components in gastric MALT lymphomas. Histopathology 1997;30:425-9.

4 Wotherspoon AC, Pan L, Diss TC, et al. Cytogenetic study of B-cell lymphoma of mucosa-associated lymphoid tissue. Cancer Genet Cytogenet 1992;58:35-8.
5 Hussell $\mathrm{T}$, Isaacson PG, Crabtree JE, et al. In vitro studies of malignant B cells from low grade $B$ cell gastric lymphoma of mucosa associated lymphoid tissue. In: Rieken EO, Zeitz M, Stallmach A, Heise W, eds. Malignancy and chronic inflammation in the gastrointestinal tract - New concepts. Dordrecht: Kluwer Academic Publishers, 1995:42-7.

6 Hussell T, Isacson PG, Spencer J. Proliferation and differentiation of tumour cells from B cell lymphoma of mucosa associated lymphoid tissue in vitro. F Pathol 1993;169:221-7.

7 Hofmann K, Bucher P, Tschopp J. The CARD domain: a new apoptotic signalling motif. Trends Biochem Sci 1997;22:155-6.

8 Thornberry NA, Lazebnik Y. Caspases; enemies within Science 1998;281: 1312-16.

9 Neurath MF, Becker C, Barbulescu K. Role of NF-кB in immune and inflammatory responses in the gut. Gut 1998;43:856-60.

10 Lee WC, Balsara B, Liu Z, et al. Loss of heterozygosity analysis defines a critical region in chromosome p22 commonly deleted in human malignant mesothelioma. Cancer Res 1996;56:4297-301.

11 Mathew S, Murty VV, Bosl GJ, et al. Loss of heterozygosity identifies multiple sites of allelic deletion on chromosome 1 in human germ cell tumors. Cancer Res 1994;54:6265-9. 